\title{
Speech Acts Analysis in Whatsapp Status Updates
}

\author{
Barzan Faizin \\ Department of Communication and Islamic Broadcasting \\ UIN Sunan Gunung Djati Bandung \\ Bandung, Indonesia \\ barzanfaizin@uinsgd.ac.id \\ Wawan Gunawan \\ Department of English Literature \\ Universitas Pendidikan Indonesia \\ Bandung, Indonesia
}

\author{
M. Ali Ramdhani \\ Department of Informatics \\ UIN Sunan Gunung Djati Bandung \\ Bandung, Indonesia
}

\author{
Dudang Gojali \\ Department of Comparative Law and Schools of Law \\ UIN Sunan Gunung Djati Bandung \\ Bandung, Indonesia
}

\begin{abstract}
This study elaborates the use of speech acts in computer-mediated communication, particularly in the whatsapp status message, to communicate in a mass medium. The study is a qualitative content analysis which applied a sample population covering a total number of 86 status messages posted by 23 participants taken in 4 consecutive days. The sample consisted of 13 male $(56.52 \%)$ and 10 female $(43.48 \%)$ from various social and educational background who ranged in age from 14 to 50 years old. The research findings point out the uniqueness of whatsapp status updates which has different result from the previous studies in terms of the frequency of speech act occurrences among participants from various social and educational backgrounds. Moreover, this provides a meaningful perspective in understanding human behavior regarding pragmatic functions and intentions of SNS users in Indonesia.
\end{abstract}

Keywords—speech acts; status updates; whatsapp

\section{INTRODUCTION}

The study of language in the present days has developed significantly hand by hand with the development of technology. With the emergence of new media technologies, people communicate and interact to each other with a very drastic transformation, in which communication tends to be more virtual in recent times. Social Network Site (SNS) is one of new media technologies that has attracted the attention and interest of the society [1]. Meanwhile, a model of ComputerMediated Communication (CMC) developed has been developing $[2,3]$. In this regard, social media and computermediated communication have been studied from a variety of perspectives in a number of disciplines, including behavioral psychology, communication studies, discourse analysis, sociolinguistics, social network analysis, and sociology [4].

It is no room for doubt, the phenomena above facilitated and encouraged people to communicate easily without a constraint of space and time. Nowadays, there are increasingly developing a lot of on-line networking for sending messages such as Whatsapp, Fb, Line, Wechat, BBM, etc. Whatsapp application constitutes a cross-platform mobile application that enables people to alternate messages without buying SMS. Whatsapp is available for all smart phones with Android,
Windows software; these telephones would all be able to message every other. In addition, based on the statistical data of social media networking, there are 1 billion users of Whatsapp in world wide. Even as in Indonesia, it's the second of the highest customers after BBM.

Due to the technological and social coverage of SNSs, the study of speech acts is seemingly relevant. Previous studies have revealed the coverage of new media to construct an identity online [5], and consequently SNS create a new medium in which people explore how to construct messages to keep and maintain their existence and relation with others online. Even though people can both send and transfer pictures, videos and music in SNSs, the main means of communication is still text. Messages are written and read in text-format, group affiliations and interests are denoted.

\section{THEORETICAL FRAMEWORK}

\section{A. Social Media}

Social Media can be seen as a form of electronic communication through which users interact to one another to create, share, exchange and discuss many things i.e. information, ideas, personal messages and other content using a multimedia mix of personal words, pictures, videos and audio, utilizing online platforms while they are connected to the internet.

\section{B. WhatsApp Technology}

WhatsApp is a form of technology commonly used on certain cellular phones and computers. Since the smart phones got popular, a great number of messaging services were launched but including WhatsApp. This application is highly attractive and can make a big impact on regular users.

Social network sites (SNSs) as web-based applications that covers three functions: 1) users construct a public or semipublic profile; 2) present a list of other users to whom an individual is connected; and 3) view and follow that list and the lists of others within the system [1] . These types of technology allow users to articulate and make their social networks visible, 
have recently taken the forefront of both commercial and academic interest.

\section{Speech Act Theory}

Speech act theory was applied due to a practical usage in the previous studies of natural language processing and computer-mediated communication [6]. Furthermore, SAT enables researchers to reveal intended meaning of status messages identified and classified as illocutionary acts. Communication implies a lot of things and it is possibly done through expression, symbol, and even body language. Meanwhile pragmatic competence is the ability to use language forms in a variety of environments, reflecting the relationships between the speakers involved and the social and cultural context of the situation. Speakers who are regarded to be "fluent" in a second language due to the grammar and vocabulary mastery of the language may still lack pragmatic competence. In this regard, they may not be able to utter a language that is socially and culturally accepted.

\section{RESUlTS AND DISCUSSION}

\section{A. Frequency of Speech Acts Occurance}

The analysis and discussion show a table that serves a quantitative calculation of the speech acts in Whatsapp status updates. The table demonstrates the total amount of speech acts appearance in order of frequency, together with their percentage distribution.

TABLE I. FREQUENCY OF SPEECH ACTS FORMS IN WHATSAPP STATUS UPDATES

\begin{tabular}{|c|c|c|c|}
\hline Speech Act Type & & Total & $\%$ \\
\hline \multicolumn{4}{|l|}{ Assertive } \\
\hline Boasting & 2 & \multirow{3}{*}{37} & \multirow{3}{*}{43.02} \\
\hline Complaining & 11 & & \\
\hline Reporting & 24 & & \\
\hline \multicolumn{4}{|l|}{ Directive } \\
\hline Commanding & 6 & \multirow{4}{*}{15} & \multirow{4}{*}{17.44} \\
\hline Requesting & 3 & & \\
\hline Advising & 2 & & \\
\hline Recommending & 4 & & \\
\hline \multicolumn{4}{|l|}{ Commisive } \\
\hline Promising & 2 & \multirow{3}{*}{5} & \multirow{3}{*}{5.81} \\
\hline Vowing & 2 & & \\
\hline Offering & 1 & & \\
\hline \multicolumn{4}{|l|}{ Expressive } \\
\hline Thanking & 6 & \multirow{5}{*}{25} & \multirow{5}{*}{29.07} \\
\hline Congratulating & 4 & & \\
\hline Pardoning & 4 & & \\
\hline Blaming & 3 & & \\
\hline Praising & 8 & & \\
\hline \multicolumn{4}{|l|}{ Declaration } \\
\hline Naming & & & 0.00 \\
\hline \multirow[t]{2}{*}{ Quotation } & 4 & 4 & 4.65 \\
\hline & & 86 & $100 \%$ \\
\hline
\end{tabular}

It can be interpreted from Table I that assertive are the most frequent speech acts, followed by expressive, directives, commissives, quotations, and no declaration.

Assertive have a total of 37 occurrences, representing $43.02 \%$ of the total status update analyzed. This finding is contrary to those of earlier studies since none of the studies had assertive as the most frequently used speech act (instead, assertive occupied either the third or fourth position in the findings, in terms of frequency) [7, 8]. This inconsistent finding is, possibly, because the felicity conditions of the assertive were not highly present for the participants of previous studies. However, the members of Whatsapp group used assertive extensively because the participants made some utterances which called upon their Whatsapp members to pay attention to, listen to or understand the speakers' psychological states.

This study positioned expressive in the second position of the most frequent used speech acts. With a total of 25 status updates, expressive constitutes 29.07 per cent of the total number of speech acts used by the participants. Naturally, expressive speech acts reveals the inward feelings of a speaker. Thus, even though this present finding is not consistent with the previous studies reviewed expressive occurred either in the first or second position. It is no room for doubt that the expressive speech acts were the most top three preferred speech act. To some extent it can be said that Whatsapp users tend to share certain experiences that lead them update their status expressing their current psychological conditions.

Following the expressive in terms of occurrence frequency is directives which appeared 15 times (17.44 per cent). This finding rejected studies where directives happen to be the first position and below the third position and of speech act. The occurrence of directives as the second most frequent speech act in this study describes that the members of Whatsapp usually post status updates that make their network members to react to, perform certain actions that the speakers command, request, advice and recommend.

Moreover, the research finding showed that the participants produced use of commisive 5 times, of the total 86 status updates analyzed, representing 5.81 per cent. This type of speech acts stood to be the fourth most frequent type of speech act, reflecting that Whatsapp users encounter self-commitment in their daily interaction and they are likely to share them with network members. Following the commisive in terms of occurrence is the speech acts of quotation that happened 4 time equivalent to 4.65 per cent. This result is inconsistent with the previous studies in which quotation occurred in the top three and four used types of speech act. The reason for quotation to be the least found speech act in the present study is possibly that Whatsapp users do not find any significance in quotation acts since such acts do not belong to the speakers themselves.

As stated in Table I, declaratives were not found within the updated status made by Whatsapp users. The absence of declaratives is not surprising and is in line with the previous research findings. 


\section{B. Frequency of Speech Acts Occurance}

In this section, the writer presents the analysis of the various types of speech acts (together with their frequency of occurrence) appeared in the Whatsapp status updates, as well as their unsaid meanings. In the beginning, it is necessary to say that the messages remain in their original forms as posted by the participants as revealed in functional discourse analysis [9].

The analysis covered five speech acts (in various proportions) made by Whatsapp in updating their status: directives, assertive, expressive, commissives and quotations.

\section{CONCLUSION}

This study attempted to examine the various types of speech acts that manifest in the WhatsApp status updates of 23 participants from various social and educational background linked to the researcher's WhatsApp network. The study revealed that four speech acts were identified in the WhatsApp status updates, with various levels of occurrence. Moreover, the study found many pragmatic meanings included in Searle's speech acts that were posted by the WhatsApp users. First of all, these findings mark WhatsApp status updates as a unique study which has different result from the previous studies. Secondly, the result shows the characteristics of discourse content on SNSs in Indonesia, especially among participants from various social and educational backgrounds.

Theoretically, this study provides a meaningful perspective in understanding human behavior. The study of online messages, in particular, will enable the researchers to identify the pragmatic functions and intentions of SNS users in
Indonesia. This study is hoped to contribute to the broad understanding of intended meaning in social interaction. This is in line with Herrings' statement that discourse involves speaker choices which are conditioned not only by purely linguistic considerations, but also by cognitive and social factors.

\section{REFERENCES}

[1] D.M. Boyd and N.B. Ellison, "Social network sites: Definition, history, and scholarship," Journal of Computer-Mediated Communication, vol. 13, pp. 210-230, 2008

[2] S.C. Herring and A. Martinson, "Assessing gender authenticity in computer-mediated language use: Evidence from an identity game," Journal of Language and Social Psychology, vol. 23 no. 4 pp. 424-446, 2004.

[3] K.W. Duthler, "The politeness of requests made via email and voicemail: Support for the hyper personal model," Journal of ComputerMediated Communication, vol. 11 no. 2, 2006.

[4] S.M. Sotillo, "Illocutionary acts and functional orientation of SMS texting in SMS social networks," Aspects of Corpus Linguistics: Compilation, Annotation, Analysis, vol. 12 no. 1 pp. 1- 14, 2012.

[5] S. Turkle, Life on the screen: Identity in the age of the internet. New York: Simon \& Schuster, 1995.

[6] J.L. Austin, How to do things with words. Cambridge: Harvard University Press, 1962.

[7] C.T. Carr, D.B. Schrok, and P. Dauterman, "Speech acts within Facebook status messages," Journal of Language and Social Psychology: 0261927X12438535, 2012.

[8] M. Nartey, A Speech Act Analysis of Status Updates on Facebook: The Case of Ghanaian University Students. Language in India www.languageinindia.com ISSN 1930-2940 13:12 December 2013.

[9] G. Brown, and G. Yule, Discourse analysis. Cambridge: Cambridge University Press, 1983. 